\title{
Traditional Music and an Organological Study of Some Musical Instruments of Plateau State, Nigeria
}

\author{
Oghenemudiakevwe Igbi \& Rebecca Ufuomaroghene Ogbeide \\ http://dx.doi./org/10.4314/ujah.v20i2.6
}

\begin{abstract}
Music is one of the oldest and most practiced arts in Nigerian traditional societies. The revered place of music in the lives of Nigerians is indisputable, as a consequence of its towering roles in nearly all communal events and activities. In Nigeria, music is utilized in diverse facets especially in religious, economic, martial, and political life of the people. In other words, it is unusual to preclude music from any societal event. Though these attributes pervade all Nigerian traditional societies, it is even more fascinating that every ethnic group or culture has their peculiar music with which they are recognized. Thus, there is bound to be dissimilarities in the manner in which various societies regard music as a concept, phenomenon, or how it functions in traditional life. The thrust of this paper therefore, is to examine music as a phenomenon, its roles in society, and how it is conceived by the people of Plateau. Data were gathered using ethnographic method, while interviews formed a significant part of the research tools. Some existing videos and those collected from the field were analysed by the authors. Findings from data gleaned reveal that there is a plethora of music types among the Plateau people. It is also gathered that music forms a fundamental aspect of life on the Plateau, and is widely used in virtually all communal events. However, research efforts into the different traditional music types of the people of Plateau need to be intensified and sustained over time, in order to document findings that will further lead to addressing the protracted challenge of dearth of literature in the traditional music of the area under study.
\end{abstract}




\section{Introduction}

Music has always played a leading role in preserving Nigeria's cultural heritage. As a powerful cultural indicator, music is constantly up there as one of the front runners in studies or discussions pertaining to culture. This is partly as a result of the ability of music to preserve and transmit itself together with other cultural values, through oral tradition and other means to several generations. It is also because of the close affiliation of music with the African man and the several roles music plays in the execution of social, religious and economic activities in Africa. Even though the research efforts into various aspects of Nigerian traditional music in the last decades is commendable, it is still imperative to note that majority of those researches are on musical types of southern Nigeria. In other words, the traditional music of the north is the least researched in Nigeria. Consequently, there is dearth of literature on music from northern Nigeria, in comparison to the barrage of scholarly output on various aspects of music from southern cultures. However, owing to the plurality of musical cultures in Nigeria, it is essential to interrogate the way each cultural entity (whether from the north or south) views music as a concept, phenomenon, and also research on how music functions in different societies. The people of Plateau for instance have different musical types that are used for different purposes. Even among the plateau, there still exist some variances in their traditional music that require systematic investigation and documentation. Findings from such research effort will not only provide a valuable source of literature to researchers and arouse more interest in the area, it will help divulge and facilitate the dissemination of vital information on various aspects of the rich musical heritage of the Plateau people. 
This paper therefore, will focus briefly on how the people plateau view music, categories/types of songs found in the different musical cultures, the functional nature of music to the people, and some of the musical instruments found in the area. The authors relied on three field assistants to collect data. They were given a total of twenty five questions generated by the authors. Data collected including those written down, and recorded in audio-visual formats were sent to the researchers via social media, and these formed the basis for writing the paper after the information gathered had been subjected to analysis. It is surmised from the research that music on the plateau is very rich, highly functional, and is seen as an absolute means of cultural expression even though the level of research on Plateau traditional music is still intangible. The paper recommends that music scholars and other cultural scientists have plentiful knowledge to garner from the traditional music of the Plateau only if more researches are conducted especially in the numerous virgin areas that still exist with regards to research.

\section{Plateau People and Their Way of Life}

Plateau State is located in central Nigeria, with Jos as its capital. The area is approximately 30, 913 kilometres, with an estimated population of three million, five hundred thousand people. This makes her the twelfth largest state in Nigeria. Plateau State has had its boundaries adjusted on a number of occasions by the government, which sometimes further led to the creation of other states like Nasarawa and Benue. The state is very diverse in linguistics, with over forty distinct languages. They include Afizere, Ngas, Ron, Amo, Anaguta, Berom, Bogghom, Buji, Chip, Gashish, Ateng, Jarawa, Jukun and others. 
Plateau people are culturally diverse; this is manifested in their music, dances, textiles, and agriculture. Despite the weighty impact of Christianity on the people's culture, there still exist traditional festivals and religion. Nzem, Berom and Nshok are typical examples of such festivals where music, dance, and other aspects of culture are exhibited. The cultural diversity of plateau is also epitomized in her position as one of the foremost tourist destinations in Nigeria. Plateau state boasts of a considerable number of artefacts, historic sites, museums, and wildlife that attract visitors and tourists from different parts of the world. In traditional societies found on the Plateau, individuals, groups and families engage in various customary practices that are peculiar to, or approved by the community. In other words, most Africans perceive culture mainly as a communal affair - where groups that exist in the community, or designated village heads ensure the promotion and sometimes strict compliance to aspects or a totality of the culture. Such communal practices are deemed an integral part of life, and an authentic medium of cultural expression. In the Plateau region of Nigeria, culture isusually exhibited in music, dance, agriculture, conjugal rites, religion, education, health care, etc. The community ensures the preservation of culture by passing it from generation to generation mainly through oral tradition. New entrants are also expected to naturally key into or live in conformity with existing laws governing the community.

\section{Concept/Classification of Music among the Plateau}

Music is the most central aspect of culture, and is seen by the typical Plateau man as a means of communication, transmission of values, part of religion, and enactment of age-long norms including tenets and ideals, and entertainment. All these are reckoned as vital to the sustenance of the people's cultural heritage and identity. 
Each society has its musical type that they practice in contexts they consider suitable to their belief systems and culture. Nettl (1997:5) observes that "each society has its own principal music, and the members of a society know and respond to their music with a kind of common understanding, just as they communicate through their language'. There is much emphasis on music and dance as a means of cultural expression and a definition of history. Plateau is one of the most multi-ethnic states in Nigeria, thus making her a very culturally diverse region. Music in Plateau traditional societies is mainly functional. Majority of the autochthonous ethnic groups possess their kinds of music. In other words, there are obvious similarities and dissimilarities between music of the various cultures in Plateau. One of such similarities is the functional nature of their music. There are songs for various purposes. Such songs may be unsuitable for performance in another context that is different from the original one that has been practiced over the years. For example, there are songs for hunting that are unsuitable for performance other than when in a hunting exercise. Unlike Western music, African music is not categorized based only on form, structure, period, linguistic structure etc, but with the roles they play in society. Plateau songs are therefore categorised according to the functions they play in society. Data gleaned from the field shows that the following categories of music exist on the Plateau.

1. Sacred Music

2. Ceremonial Music

3. Entertainment Music

4. Royal Music

5. Festivity Music 
The categories above can be further divided into dirges, songs for marriages, praise songs for royalty or celebrities who have distinguished themselves in the community, birth songs, lullabies, and satirical songs for mocking individuals who may have erred in society.

\section{Hausa}

Mwale-le mwale-le woamarya Mwale-le yimwalewoamarya

Yi jiwulryang - ah amarya Yi nwanlewo muni kadyiwo

Yi nwanlewo

\section{English Translation}

Welcome, welcome our wife

Welcome, you are welcome, our wife

Hope you arrived safely, our wife You are welcome, we congratulate you

You are welcome our wife

Furthermore, various festivals are celebrated from time to time on the Plateau. Among the Berom for example, Nzem Berom festival is celebrated in April every year to mark the advent ofa new rainy season. Commenting on the festivals in most Nigerian communities, Okafor (2004) in Okafor and Okafor (2009:3) notes: Some ethnic groups and communities have at least one festival or ceremony every month... Traditional festivals and ceremonies whose rituals, music and decorative arts have tourism attractions include the following:- commemorative royal festivals, change of year festivals, fishing festivals and regatta, deity festivals, anniversaries of coronations, communal and historic events, cultural pageants, which occur after a long time, rare masquerade (spirit-manifest) festivals, and traditional wrestling festivals.

Mandyeng is another festival of the Berom people that is also celebrated in April every year to usher in the new yam harvest. Among the Aten people, Wuru Dagarang is celebrated yearly on $15^{\text {th }}$ December to commemorate the anniversary of 
migration by ancestors who lived in a cave to a new settlement on land. Wushiri festival is celebrated in January to offer thanksgiving for a bounteous agricultural harvest.

\section{Musical Instruments on the Plateau}

African traditional societies have a plethora of musical instruments including drums, strings woodwinds, brasses, etc. Aluede (2016:39) rightly notes that 'Africa is not only a land of drums but many other musical instruments and that these instruments are versions of what are obtainable in occidental worlds'. There is a vast array of musical instruments among the Plateau. Instruments found among the Mushere, Ron and Berom include plucked instruments, rattles of different types, blown instruments, and struck instruments. However, they shall be discussed in this paper as idiophones, membranophones, chordophones and aerophones, as classified by Curt Sachs and Von Hornbostel (in Klaus Wachsmann, 1961).

\section{Idiophones}

Idiophones can either be pitched or unpitched - pitched idiophones being those that are capable of producing definite tones, while unpitched as those that produce indefinite tones. The most common type of pitched idiophone found on the Jos Plateau is the xylophone popularly called kundung. Unpitched idiophones include different types of rattles, bells, gourds and scrappers. The most popular xylophones in Plateau are those in which animal (especially cattle horns) horns serve as resonators. Some of the instruments like gourd rattles have been modified in recent times. For example, in some Plateau communities, the gourds have been replaced with tins containing stones, beads or dry plant seeds. 
Sound is produced when the tins are shaken. The gourds can be played in different ways. One of the most fascinating traditional music of northern Nigeria that one of these authors came across was in Warri, Delta State, where an ensemble consisting entirely of women and mostly those of Boze origin used the gourd in a very intriguing way during a performance. The gourd was capsized in a basin of water. As the player used her left hand to control the degree of immersion of the gourd in water, the other hand played the instrument. Up to three tones were produced, depending on the pressure of air enclosed in the gourd. There are also rattles worn mostly by women on the ankles during performances. The rattles synchronize rhythmically with the dance movements, as the feet are stamped on the ground.

\section{Membranophones}

This consists of instruments made with membranes that are played with the hands or beaten with sticks. Drums are very fundamental to music making in Plateau. There are single and double-headed tension drums of varying sizes, pitches and depth. Kalanguu, ibarakadin, and igangan are typical examples of drums found in Plateau musical ensembles. The kalanguu is also known as hourglass drum. It is held under the arm during performance, and the player uses a stick usually curved at the end to beat the drum. It is capable of playing many pitches thereby producing speech tones that make it suitable for flattering or praising nobles in the community. In recent times, kalanguu and ibarakadin have been utilized by secular music ensembles; this has however not affected their use in praising village chiefs. Iganganon the other hand, is a double-headed drum used to accompany various secular dances and songs. Kung is found mainly among the Mushere and its membrane is made from leopard skin. 


\section{Chordophones}

Strings rank among the most commonly found instruments on the Plateau. There are lutes, zithers, and harps. Stringed instruments can be found among the Berom, Eten and Tarok. Examples are yomwaya, and ingangon. Yom Nshiis a banjo usually made of two strings, a calabash and skin that serve as resonators. The gulum is a well - known three stringed harp found in most Plateau communities. Gogeand kukuma are also other forms of harp that are single-string, and are often fastened to a calabash resonator. The most widespread of zithers in Plateau is the raft-zither called molonkara. It is found among the Eggon and Angas people. Another popular stringed instrument is garaya. It is a two-string instrument with an interval of a fifth between the strings, and is regularly used for spiritual purposes. Sound produced by the instrument is conceived as praise being offered to the gods. The music elicits dance steps that are thought to be inspired by spirits. Akpabot (1986:13) notes that a garaya 'listener, usually a woman, requests a tune on the instrument and dances so wildly to the music that she collapses on the ground in a faint and is carried away to be revived'.

\section{Aerophones}

Aerophones come in different types and sizes. These include oboes, horns, clarinets, pan-pipes, and whistles. They are either end-blown or side-blown. A typical example of an end-blown trumpet found among the Jos Plateau people is the kakaki. It is a very long metal instrument with several tones. It is utilized mainly in royal ceremonies like coronations and conferment of titles. It is also used to announce the arrival of a king, or other very important personnel to an event. Algeita is another musical instrument used 
primarily in royal courts. It is a double reed instrument that may be further classified into the oboe family. It has the shape of a funnel, and produces sharp nasal tones. The instrument is used for communication especially in royal functions. The player uses the algeita to announce the arrival of or, to eulogize first class dignitaries like kings and high - ranking chiefs to events. In most cases, the services of singers are employed to interpret the exact eulogies being dished out by the algeita player. The importance of kakaki and algeita to royalty is so immense that it is a primary part of an emir's convoy. Some of the kakaki and algeita players may even be afforded freedom to live in the palace. Such royal gesture is usually followed by unending tunes meant to laud and extol the virtues of the king. The king in turn reciprocates by doling cash or material gifts to the musicians. It is noteworthy that having musicians in the palace who play praise tunes, or who form part of the king's entourage when gracing an important event, confers more dignity on the king and elicits some inner feeling of pride especially when in the midst of other kings. 
Igbi \& Ogbeide: Traditional Music and an Organological Study of Some Musical Instruments of Plateau State, Nigeria

Photos of Some Commonly Found Musical Instruments in Plateau Communities

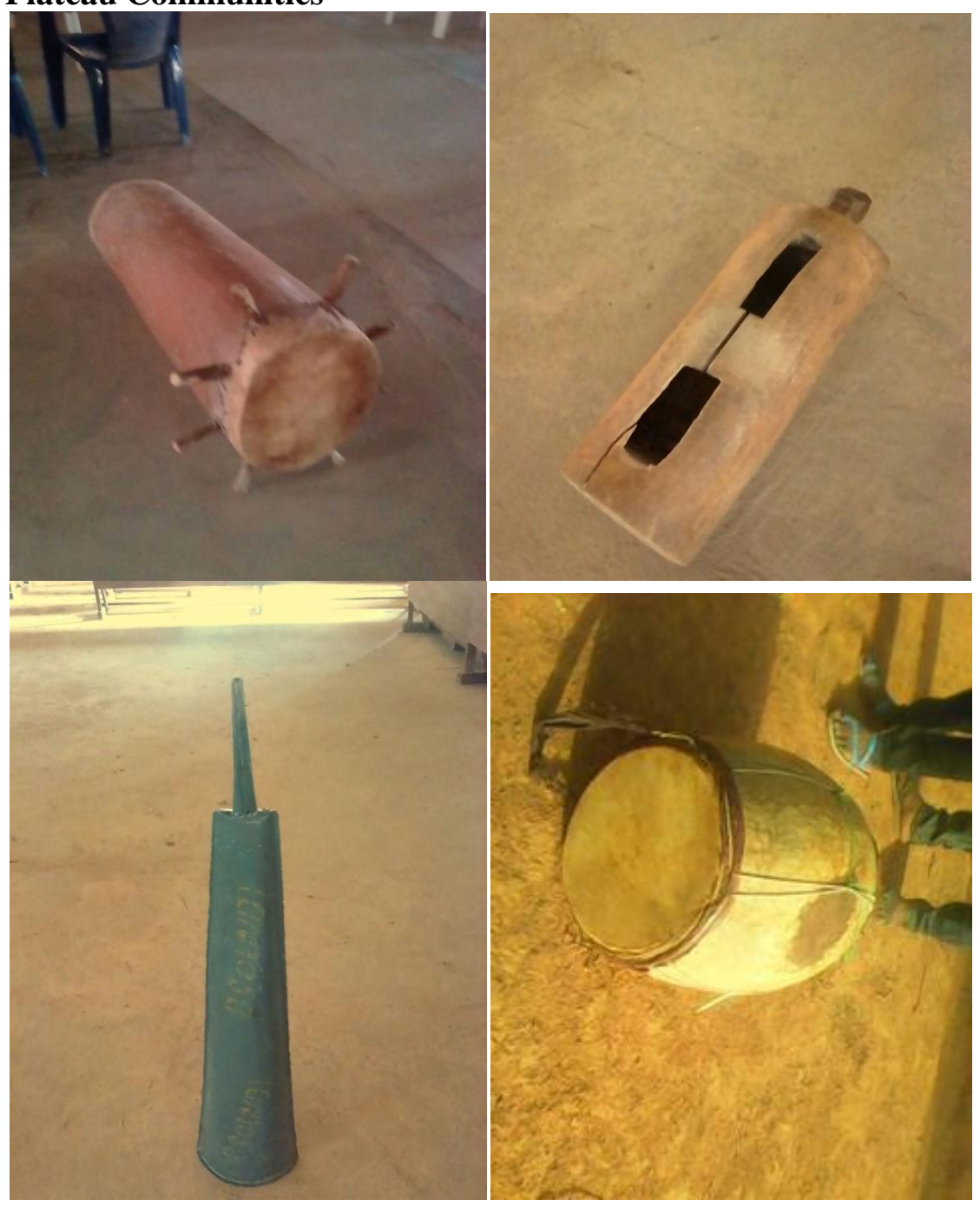




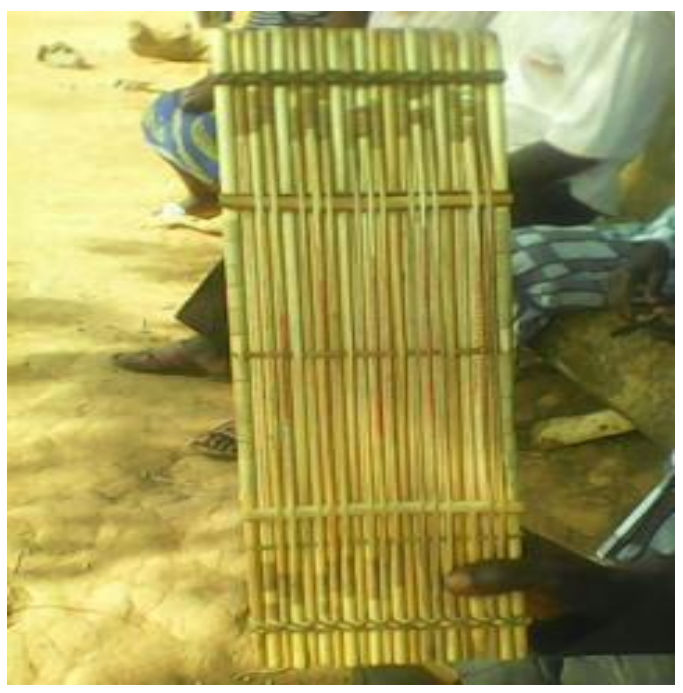

\section{Functional Aspects of Music in Plateau Traditional Life}

African traditional music is a product of creativity and syncretism, usually involving other aspects like dance, drama and poetry. 'Music that is integrated with dance is more prevalent in African societies...' (Ozah, 2018:30). It is firmly rooted in culture and transmitted through oral tradition. As a phenomenon, music in Africa is not absolutely conceived only in terms of sound, but rather as a combination of sound with the other cultural elements listed above. It promotes both individual and communal participation with a view to achieving leisure, enhancing work, soliciting supernatural blessings, facilitating healing, or instilling discipline and fostering moral etiquette. According to Idolor, (1991:1), 'traditional music is humanly organized sound by an individual, group of individuals or a community based on moral and aesthetic principles acceptable to a given population'. In whichever light music is seen, its functional nature in African 
traditional societies cannot be in doubt. Furthermore, that music is a ubiquitous art has long been established in literature. Music is an integral part of life in Africa, and it plays indispensable roles in the everyday life of Africans. Historical and anthropological data have proven that music is directly connected to man's social, religious, and traditional life. Among the Plateau people for example, celebrations like coronations, burials, births, and festivals usually involve a lot of singing, drumming and dancing. Music is also utilized for more specific purposes like the use of musical instruments to announce a bad omen, or the arrival of a celebrity to an event. It is also used to convene village meetings, or as accompaniment to various dances. In other words, music is used for different forms of communication between members of a community, and with spiritual forces. For example, among the Ron and Mushere, Domatar and Pwaghal music types are used only for hunting. Women are forbidden from performing Pwaghal music type since only men engage in hunting. Domakungo music is also performed during marriage celebrations among the Ron.

\section{Conclusion and Recommendation}

The paper centered on the classification of musical instruments, and attempted an overview of the roles of music in the day-to-day lives of Plateau people. It was gathered from the study that music is not just practiced for sheer entertainment, but also perform other explicit roles as they relate to man's social and religious activities in society. The musical instruments used in ensembles in Plateau were also classified, and some of their specific roles were discussed. The study reveals again that the place of music in all spheres of human endeavour is incontestable. Even though this fact has continued to form a large corpus of scholarly discourse in the 
field of African musicology, it is noteworthy that one cannot tire with constantly reiterating the enormous benefits and roles of traditional music in society. It seems to us (the authors) that each time a new publication on any aspect of African music appears, it further substantiates the fact that music is inevitable to life in Africa. Furthermore, there are still many areas of African music that are yet to be captured in literature, and even when such areas have been addressed, there will still be gaps that other researches could fill. One of such areas of culture lacking in terms of scholarly output is the traditional music of Plateau. Despite the very intriguing history and other aspects of music in the region and the several years of academic music study in Nigeria, there is still the lingering challenge of the abysmally low number of erudite literature on music from the Plateau and even northern Nigeria in general. In view of this, it is recommended that more research endeavour into the music of the northern region should be encouraged, and results from such efforts published. Even though Nigerian music scholars often promote music from their cultural milieu by conducting research on musical types and practices of their area, Ogisi (2017:570) reminds us that Nigerians are '...a multi-musical people who are able to appreciate their music and those from other cultures akin to a people who speak their mother tongue as well as other languages'. Nketia (2016:16) also states that the study of African musicology means 'studying not only the musical traditions of my own society and those of other societies in Ghana as sources of knowledge and practice, but also extending my enquiry at the appropriate time to the traditions of societies in West Africa and other parts of sub-Saharan Africa...' By implication, Ogisi and Nketia's comments suggest that Africans are free to study music of other cultures that may not necessarily be theirs, just as these authors have done. This will no doubt 
facilitate and promote the intermingling of musical knowledge and cultures, and also ensure the survival of those cultures by documenting findings that several generations to come will continue to benefit from.

\section{Oghenemudiakevwe Igbi}

Department of Music

College of Education, Agbor mudiaigbi@gmail.com

$\boldsymbol{\&}$

Rebecca U. Ogbeide

Department of Music

Delta State University,

Abraka

silobogbest2016@gmail.com 


\section{References}

Akpabot, S. E. (1986). Foundation of Nigerian Music. Ibadan: Spectrum Books.

Aluede, C. O. (2016). 'Emplacing African Musical Instruments in the Development of Music Education in Nigeria: Issues and Counter Issues'. Journal of Nigerian Music Education. No. 8. Pp: $39-54$.

Idolor, E. G. (1991). 'Okpe Traditional Music: the State of the Art'. A Paper Presented at the Okpe National Festival of Arts and Culture, Held in Orerokpe, in 1991. Pp: 1-14.

Nettle, B. (1997). 'Introduction: Studying Musics of the World's Cultures'. In Bruno Nettle et al. Excursions in World Music. Second Edition. New Jersey: Prentice-Hall, Inc. Pp: $1-13$.

Nketia, J. H. K (2016). Reinstating Traditional Music in Contemporary Contexts. Ghana: Regnum Africa Publications.

Ogisi, A. A. (2016). 'A Historical Appraisal of the Role of Technology and Music in Acculturation Process in $20^{\text {th }}$ Century Nigeria'. In Eni, K. E., Binebai, B., and Ikibe, S. O. (Eds). Music Scholarship, Culture and Performance Challenges in 21st Century Africa: A Critical Resource Book in Honour of EmurobomeIdolor. Lagos: Bahiti and Dalila Publishers. Pp: 556 - 571.

Okafor, R. C. and Okafor, C. (2009). Music and National Development in Nigeria. Enugu: New Generation Books.

Ozah, M. (2018). 'Egwu Amala: Gender Issues in African Traditional Music and Dance'. Journal of the Association of Nigerian Musicologists. No. 12. Pp: $24-37$. 